\title{
RESEARCH
}

Open Access

\section{High prevalence of asymptomatic malaria in south-eastern Bangladesh}

Peter Starzengruber ${ }^{1,2,3}$, Hans-Peter Fuehrer ${ }^{1,2,4}$, Benedikt Ley ${ }^{1,2}$, Kamala Thriemer ${ }^{1,2}$, Paul Swoboda ${ }^{1,2}$, Verena Elisabeth Habler ${ }^{1,2}$, Mariella Jung ${ }^{1,2}$, Wolfgang Graninger ${ }^{3}$, Wasif A Khan ${ }^{5}$, Rashidul Haque ${ }^{5}$ and Harald Noedl ${ }^{1,2^{*}}$

\begin{abstract}
Background: The WHO has reported that RDT and microscopy-confirmed malaria cases have declined in recent years. However, it is still unclear if this reflects a real decrease in incidence in Bangladesh, as particularly the hilly and forested areas of the Chittagong Hill Tract (CHT) Districts report more than $80 \%$ of all cases and deaths. surveillance and epidemiological data on malaria from the CHT are limited; existing data report Plasmodium falciparum and Plasmodium vivax as the dominant species.
\end{abstract}

Methods: A cross-sectional survey was conducted in the District of Bandarban, the southernmost of the three Hill Tracts Districts, to collect district-wide malaria prevalence data from one of the regions with the highest malaria endemicity in Bangladesh. A multistage cluster sampling technique was used to collect blood samples from febrile and afebrile participants and malaria microscopy and standardized nested PCR for diagnosis were performed. Demographic data, vital signs and splenomegaly were recorded.

Results: Malaria prevalence across all subdistricts in the monsoon season was 30.7\% (95\% Cl: 28.3-33.2) and 14.2\% (95\% Cl: 12.5-16.2) by PCR and microscopy, respectively. Plasmodium falciparum mono-infections accounted for 58.9\%, P. vivax mono-infections for $13.6 \%$, Plasmodium malariae for $1.8 \%$, and Plasmodium ovale for $1.4 \%$ of all positive cases. In $24.4 \%$ of all cases mixed infections were identified by PCR. The proportion of asymptomatic infections among PCR-confirmed cases was $77.0 \%$, oligosymptomatic and symptomatic cases accounted for only 19.8 and $3.2 \%$, respectively. Significantly $(p<0.01)$ more asymptomatic cases were recorded among participants older than 15 years as compared to younger participants, whereas prevalence and parasite density were significantly $(p<0.01)$ higher in patients younger than 15 years. Spleen rate and malaria prevalence in two to nine year olds were 18.6 and 34.6\%, respectively. No significant difference in malaria prevalence and parasite density was observed between dry and rainy season.

Conclusions: A large proportion of asymptomatic plasmodial infections was found which likely act as a reservoir of transmission. This has major implications for ongoing malaria control programmes that are based on the treatment of symptomatic patients. These findings highlight the need for new intervention strategies targeting asymptomatic carriers.

Keywords: Malaria, Prevalence, Asymptomatic, Bangladesh, PCR, Microscopy

\footnotetext{
* Correspondence: harald.noedl@meduniwien.ac.at

'Institute of Specific Prophylaxis and Tropical Medicine, Medical University of Vienna, Kinderspitalgasse 15, Vienna 1090, Austria

${ }^{2}$ MARIB, Malaria Research Initiative Bandarban, Bandarban, Bangladesh

Full list of author information is available at the end of the article
}

\section{Biomed Central}

(c) 2014 Starzengruber et al.; licensee BioMed Central Ltd. This is an Open Access article distributed under the terms of the Creative Commons Attribution License (http://creativecommons.org/licenses/by/2.0), which permits unrestricted use, distribution, and reproduction in any medium, provided the original work is properly cited. The Creative Commons Public Domain Dedication waiver (http://creativecommons.org/publicdomain/zero/1.0/) applies to the data made available in this article, unless otherwise stated. 


\section{Background}

The World Health Organization (WHO) estimated 660,000 deaths in 2011 directly attributed to malaria, approximately half of the world's population being at risk of infection [1]. The disease has re-emerged in several Central Asian countries and in Southeast Asia partly because of relenting malaria control efforts and the emergence of parasite resistance to the most commonly used anti-malarial drugs [2]. In many regions the vectors have become resistant to the main insecticides and cases of artemisinin resistance have been reported from the Greater Mekong subregion [3-6].

Resistance to chloroquine and sulphadoxine/pyrimethamine (S/P) has been reported from Bangladesh [1] but until now there is no evidence that artemisinin resistance has spread westwards to Bangladesh, which traditionally forms a gateway to the Indian Subcontinent [7].

In 2004 the Ministry of Public Health and Family Welfare of Bangladesh revised the malaria treatment guidelines, introducing artemisinin-based combination therapy (ACT) in areas with resistance against chloroquine and S/P [1]. However, ACT was not deployed on a major scale until 2007. Despite the introduction and distribution of ACT in the last years the WHO reports a 70\% increase in case numbers between 2000 and 2010 in Bangladesh. However, it is difficult to discern the underlying trend in malaria incidence from improved reporting due to continuous improvements in diagnostic facilities [8]. A seemingly contradictory statement was given in the 2012 report where a decrease of $69 \%$ in malaria case incidence between 2000 and 2011 has been reported [1]. Due to a shortage of staff in health care facilities and shortcomings in surveillance and information systems there is still a significant lack of data on malaria from this area $[9,10]$. Further increasing drug resistance is significantly aggravating the malaria situation and treatment alternatives to currently used antimalarials are missing [11-14].

In 2007 a rapid diagnostic test (RDT)-based, crosssectional survey in 13 eastern districts of the country showed malaria to be endemic within the entire study area. Overall prevalence was reported to be approximately $4 \%$, the majority of cases $(90.2 \%)$ due to Plasmodium falciparum. Plasmodium vivax and mixed infections accounted for only $5.3 \%$ and $4.5 \%$, respectively. Highest prevalence rates were reported from the Chittagong Hill Tract (CHT) with up to 15\% [15]. Surveys among febrile patients in the region showed a malaria positivity rate of $26 \%$ by microscopy (Swoboda et al. personal communication), which increases to $50 \%$ when using polymerase chain reaction (PCR), a considerably more sensitive diagnostic tool [16].

The high sensitivity of PCR allows detecting subpatent infections that are frequently asymptomatic and it has been shown that those undetected infections represent a considerable fraction of overall infections and may therefore act as a reservoir for transmission [17-21]. The aim of this study was therefore to assess prevalence and proportion of asymptomatic $P$. falciparum infections in the southernmost district of the CHTs.

\section{Methods}

\section{Study setting and procedure}

Two cross-sectional surveys were performed: the first during the rainy season from August to October 2007 and the second during the dry season from December 2007 to February 2008. The study was conducted by a team from the Medical University of Vienna, Austria in collaboration with the International Centre for Diarrhoeal Disease Research, Dhaka, Bangladesh (ICDDR, B). All selected communities were visited by members of the study team, prior to sample collection to inform villagers about the ongoing study. Laboratory tests on collected samples and data analysis were carried out at the Malaria Research Initiative Bandarban (MARIB) field research centre in Bandarban town. Written informed consent was obtained from all study participants or their legal representative, the study protocol was approved by the Ethical Review Committee of the International Centre for Diarrhoeal Disease Research, Bangladesh (ICDDR, B).

\section{Sampling}

Administratively, Bandarban District consists of seven subdistricts (upazilas), 32 unions, 140 mouzas and 1,482 villages. Geographical multistage cluster sampling techniques in a single domain were employed (Figure 1) using population figures from the 2001 census [22]. For each of the seven subdistricts all mouzas or villages were listed alphabetically and 3 mouzas or villages were randomly selected using a probability proportion to size (PPS) sampling procedure. A list of all households within the mouza or village was prepared and 20 households per mouza or village were randomly selected. All the persons present in the household were invited to participate in the survey.

During the monsoon season 2007 a total of 21 villages in all seven subdistricts were surveyed (Survey I). Eight villages in three subdistricts (Bandarban, Ruma and Rowangchari) were revisited during the second survey period (Survey II). Whenever possible the study team visited the same households as in the previous survey. Household members who declined to participate or had moved away from the area were replaced by their closest neighbouring household.

\section{Data and sample collection}

Participants were interviewed and information was recorded on gender, age, ethnicity, occupation, height, 


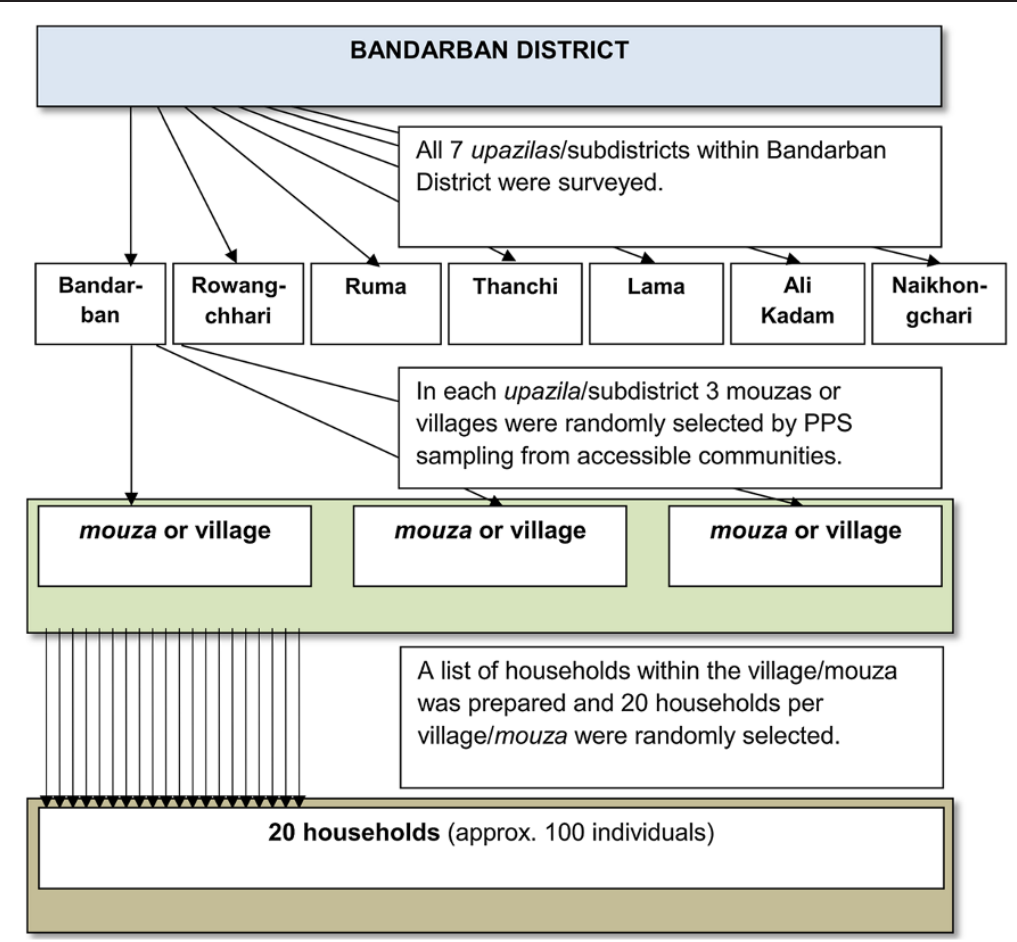

Figure 1 Flow chart for selecting clusters and households within Bandarban District. *PPS (probability proportional to size).

weight, history of fever, number of previous episodes of malaria/fever, last date of malaria diagnosis and result of diagnosis, source and drugs used in malaria treatment, and the number of household members. Axillary temperature and pulse were measured in all participants. Three $\mathrm{ml}$ of venous blood was collected from participants eight years or older for malaria RDT/microscopy and $100 \mu \mathrm{l}$ of venous blood transferred on filter paper (903; Schleicher \& Schuell, BioScience GmbH, Dassel, Germany) in duplicate. Five drops of blood (one drop of blood for the malaria RDTs, two for microscopy, and two drops of blood for the PCR filter paper) were drawn by finger or heel prick from children below eight years old.

\section{Laboratory methods}

Malaria was diagnosed in the field by RDT and later confirmed by microscopy and PCR.

\section{Rapid diagnostic test}

RDTs (FalciVax ${ }^{\circ}$, Zephyr Biomedicals, India) based on the detection of $P$. falciparum-specific histidine-rich protein 2 (HRP2) and P. vivax-specific lactate dehydrogenase (Pv-pLDH) were employed in all participants with malaria-like symptoms [23,24]. Patients who tested positive were provided with immediate treatment following national guidelines. Febrile patients considered seriously ill were immediately referred to the closest health care facility for further diagnosis and treatment.

\section{Microscopy}

Giemsa-stained blood smears were used for microscopic diagnosis of malaria following established standard operating procedures (SOPs). Thick and thin blood films were prepared, stained with Giemsa stain (Merck ${ }^{\bullet}$, Darmstadt, Germany) and examined under an oil immersion (Olympus microscope CX21, Tokyo, Japan) for parasite positivity and species determination. Declaring a slide positive or negative and initial species diagnosis was based on the examination of 200 fields in thick films. A slide was considered positive when at least one parasite was found. After finding the first parasite another 200 fields were completed to rule out mixed infections. If no parasite was found in 200 oil fields the slide was considered negative. Parasite density was calculated by counting the number of asexual malaria parasites per 200 white blood cells (WBCs) assuming a WBC count of $8,000 / \mu \mathrm{L}$ [25].

\section{Quality control}

A minimum of $5 \%$ of all positive and negative slides were randomly selected for internal quality control.

\section{Polymerase chain reaction (PCR)}

PCR was performed to assess the malaria prevalence in both, symptomatic and asymptomatic participants. DNA 
was isolated from filter papers using a modified chelexbased technique $[26,27]$. Nested PCR assays and Plasmodium genus-specific primers rPLU1/rPLU5 were used for the Nest1 amplification and rPLU3/rPLU4 for Nest2 reactions as described previously [28-30]. All genusspecific PCR-positive results were analysed to species level using the following species-specific primers as reported previously: rFAL1/rFAL2 (P. falciparum); rVIV1/rVIV2 (P. vivax); rMAL1/rMAL2 (P. malariae); rOVA1WC/ rOVA2WC (Plasmodium ovale curtisi and Plasmodium ovale wallikeri); rOVA1/rOVA2 (P. ovale curtisi); rOVA1var/rOVA2var (P. ovale wallikeri) [28-33].

\section{Case definition}

Symptomatic clinical malaria cases were defined as PCRpositive individuals with documented fever (axillary temperature $\geq 37.5^{\circ} \mathrm{C}$ ) and reported clinical symptoms consistent with malaria in the previous seven days. Oligo-symptomatic malaria cases were defined as PCRpositive, afebrile (axillary temperature $<37.5^{\circ} \mathrm{C}$ ) cases with a reported history of fever or illness in the previous seven days. Asymptomatic malaria cases were defined as PCR-positive cases without measurable fever (axillary temperature $<37.5^{\circ} \mathrm{C}$ ), who reported no malaria-related symptoms, and had not received treatment for malaria in the previous seven days [34].

\section{Splenomegaly}

The spleen rate was determined for children aged 14 years and below. Spleen size was measured following the method established by Hackett [35] and classified either as negative (Hackett grade 0) or positive (Hackett grades $1-5)$.

\section{Classification of malaria endemicity}

The four classes of endemic malaria were defined as following [35]: hypo-endemic malaria: spleen and/or parasite rate in children two to nine years not exceeding 10\%; meso-endemic malaria: spleen and/or parasite rate rate in children two to nine years between 11 and 50\%; hyperendemic malaria: spleen and/or parasite rate rate in children two to nine years constantly over $50 \%$ and a high spleen and/or parasite rate rate in adults (over 25\%); holo-endemic malaria: spleen and/or parasite rate rate in children two to nine years constantly over $75 \%$, but a low spleen and/or parasite rate rate in adults.

\section{Statistical analysis}

$\mathrm{P}<0.05$ was considered significant. Pearson's Chi-square with Yates' correction or Fisher's Exact test as appropriate were used for categorical data, Mann-Whitney $U$-test was performed for comparing continuous data that did not conform to normal distribution. Student's $t$-test was conducted to evaluate differences between quantitative variables that were normally distributed. All analyses were performed using Microsoft Excel $^{\circ}$ and VassarStats [36].

\section{Results}

\section{Demographic data of the study population}

A total of 1,418 individuals in 416 households from 21 villages were included in the first survey and 436 were revisited and included in the second survey. The male/ female ratio was 0.84 . The median age was 24 years (IQR 9-40). The distribution of the different age groups is shown in Table 1.

Malaria prevalence and fever in cross-sectional survey I District-wide malaria prevalence (Table 2): Malaria prevalence across all subdistricts in the monsoon season was $30.7 \%$ (95\% CI: $28.3-33.2)$ and $14.2 \%$ (95\% CI: 12.5 16.2) by PCR and microscopy, respectively. Of the 1,418 samples collected 435 (30.7\%, 95\% CI: 28.3-33.2) were PCR-positive. Plasmodium falciparum accounted for $58.9 \%(\mathrm{~N}=256,95 \% \mathrm{CI}: 54.1-63.5)$, P. vivax for $13.6 \%$ $(\mathrm{N}=59,95 \% \mathrm{CI}: 10.6-17.2)$, P. malariae for $1.8 \%(\mathrm{~N}=8$, 95\% CI: 0.9-3.7) and P. ovale for $1.4 \%(\mathrm{~N}=6,95 \% \mathrm{CI}$ : 0.6-3.1) of all malaria-positive individuals by PCR. The remaining $24.4 \% \quad(\mathrm{~N}=106,95 \% \quad \mathrm{CI}: 20.5-28.7)$ were

Table 1 Baseline characteristics of the study population

\begin{tabular}{lll}
\hline $\begin{array}{l}\text { Total number of } \\
\text { individuals 1,874 }\end{array}$ & & \\
& Summer survey I & Winter survey II \\
\hline No of individuals & 1,418 & 436 \\
Sex & & \\
Male & 647 & 178 \\
Female & 771 & 258 \\
Median age (IQR) & $24(9-40)$ & $29(12-45)$ \\
Age groups (years) & Male/female & Male/female \\
0-7 & $133 / 137(19.0 \%)$ & $42 / 45(20.0 \%)$ \\
$8-14$ & $115 / 133(17.5 \%)$ & $20 / 19(8.9 \%)$ \\
15-21 & $57 / 98(10.9 \%)$ & $10 / 28(8.7 \%)$ \\
22-50 & $254 / 318(40.3 \%)$ & $72 / 127(45.6 \%)$ \\
$>50$ & $88 / 85(12.2 \%)$ & $34 / 39(16.7 \%)$ \\
Mean weight kg (range) & $39(5-96)$ & $41(7-113)$ \\
Mean height cm (range) & $138(50-180)$ & $140(50-190)$ \\
Occupations & & \\
None (students, children) & $551(38.9 \%)$ & \\
Farmer & $546(38.5 \%)$ & \\
Household & $165(11.6 \%)$ & \\
Business/service & $57(4.0 \%)$ & \\
Unemployed/retired & $38(2.7 \%)$ & \\
Others & $61(4.3 \%)$ & \\
\hline
\end{tabular}


Table 2 Malaria prevalence, parasite density in Bandarban District (Survey I) Bandarban district

\begin{tabular}{|c|c|c|c|c|c|c|c|}
\hline & \multirow[b]{2}{*}{ No. } & \multicolumn{6}{|l|}{ PCR/Microscopy } \\
\hline & & P.f. & P.v. & P.m. & P.o. & Mixed & Negative \\
\hline \multicolumn{8}{|l|}{ Sex } \\
\hline Male & 647 & 122/77 (18.9/11.9\%) & $26 / 17$ (4.0/2.6\%) & $3 / 0(0.5 / 0.0 \%)$ & $3 / 0(0.5 / 0.0 \%)$ & $66 / 3(10.2 / 0.5 \%)$ & $427 / 550(66.0 / 85.0 \%)$ \\
\hline Female & 771 & 134/84 (17.4/10.9\%) & $33 / 20(4.3 / 2.6 \%)$ & $5 / 0(0.6 / 0.0 \%)$ & $3 / 0(0.4 / 0.0 \%)$ & $40 / 1(5.2 / 0.1 \%)$ & $556 / 666(72.1 / 86.4 \%)$ \\
\hline \multicolumn{8}{|l|}{ Male/Age (years) } \\
\hline $0-7$ & 133 & $17 / 20(12.8 / 15.0 \%)$ & $9 / 6(6.8 / 4.5 \%)$ & 0/0 (0.0/0.0\%) & 0/0 (0.0/0.0\%) & $7 / 1(5.3 / 0.8 \%)$ & $100 / 106(75.2 / 79.7 \%)$ \\
\hline $8-14$ & 115 & $25 / 25(21.7 / 21.7 \%)$ & $5 / 2(4.3 / 1.7 \%)$ & $1 / 0(0.9 / 0.0 \%)$ & 0/0 (0.0/0.0\%) & 23/1 (20.0/0.9\%) & 61/87 (53.0/75.7\%) \\
\hline $15-21$ & 57 & 15/6 (26.3/10.5\%) & $0 / 4(0.0 / 7.0 \%)$ & 0/0 (0.0/0.0\%) & 0/0 (0.0/0.0\%) & $5 / 0(8.8 / 0.0 \%)$ & $37 / 47$ (64.9/82.5\%) \\
\hline $22-50$ & 254 & 49/20 (19.3/7.9\%) & $11 / 4(4.3 / 1.6 \%)$ & $1 / 0(0.4 / 0.0 \%)$ & $3 / 0(1.2 / 0.0 \%)$ & 27/1 (10.6/0.4\%) & $163 / 229(64.2 / 90.2 \%)$ \\
\hline$>50$ & 88 & 16/6 (18.2/6.8\%) & $1 / 1(1.1 / 1.1 \%)$ & $1 / 0(1.1 / 0.0 \%)$ & 0/0 (0.0/0.0\%) & $4 / 0(4.5 / 0.0 \%)$ & 66/81 (75/92.0\%) \\
\hline \multicolumn{8}{|l|}{ Female/Age (years) } \\
\hline $0-7$ & 137 & 26/30 (19.0/21.9\%) & 10/8 (7.3/5.8\%) & $1 / 0(0.7 / 0.0 \%)$ & $1 / 0(0.7 / 0.0 \%)$ & 12/0 (8.8/0.0\%) & 87/99 (63.5/72.3\%) \\
\hline 8-14 & 133 & $30 / 25(22.6 / 18.8 \%)$ & $6 / 5(4.5 / 3.8 \%)$ & $1 / 0(0.8 / 0.0 \%)$ & 0/0 (0.0/0.0\%) & $14 / 1(10.5 / 0.8 \%)$ & $82 / 102(61.7 / 76.7 \%)$ \\
\hline $15-21$ & 98 & 23/5 (23.5/5.1\%) & $2 / 2(2.0 / 2.0 \%)$ & $1 / 0(1.0 / 0.0 \%)$ & 0/0 (0.0/0.0\%) & $4 / 0(4.1 / 0 \%)$ & 68/91 (69.4/92.9\%) \\
\hline $22-50$ & 318 & 47/22 (14.8/6.9\%) & $13 / 5(4.1 / 1.6 \%)$ & $2 / 0(0.6 / 0.0 \%)$ & $1 / 0(0.3 / 0.0 \%)$ & 10/0 (3.1/0.0\%) & 245/291 (77.0/91.5\%) \\
\hline$>50$ & 85 & $8 / 2(9.4 / 2.4 \%)$ & $2 / 0(2.4 / 0.0 \%)$ & 0/0 (0.0/0.0\%) & $1 / 0(1.2 / 0.0 \%)$ & 0/0 (0.0/0.0\%) & 74/83 (87.1/97.6\%) \\
\hline Parasite density/Age (years) & & $0-7$ & \multicolumn{2}{|c|}{$8-14$} & $15-21$ & $22-50$ & $>50$ \\
\hline P.f. (parasites $/ \mu$ l blood $\left.{ }^{1}\right)$ & & 993 & \multicolumn{2}{|c|}{954} & 388 & 525 & 220 \\
\hline 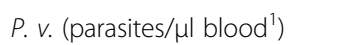 & & 425 & \multicolumn{2}{|c|}{407} & 263 & 346 & $960^{2}$ \\
\hline \multicolumn{8}{|l|}{ Subdistrict } \\
\hline Rowangchhari & 184 & $50 / 31(27.2 / 16.8 \%)$ & $10 / 9(5.4 / 4.9 \%)$ & 0/0 (0.0/0.0\%) & $1 / 0(0.5 / 0.0 \%)$ & 29/1 (15.8/0.5\%) & 94/143 (51.1/77.7\%) \\
\hline Thanchi & 218 & 62/41 (28.4/18.8\%) & $15 / 7(6.9 / 3.2 \%)$ & $0 / 0(0.0 / 0.0 \%)$ & $1 / 0(0.5 / 0.0 \%)$ & $21 / 0(9.6 / 0.0 \%)$ & $119 / 170(54.6 / 78.0 \%)$ \\
\hline Bandarban Sadar & 219 & $52 / 27(23.7 / 12.3 \%)$ & 6/7 (2.7/3.2\%) & $2 / 0(0.9 / 0.0 \%)$ & 0/0 (0.0/0.0\%) & $18 / 3(8.2 / 1.4 \%)$ & $141 / 182(64.4 / 83.1 \%)$ \\
\hline Ruma & 212 & $41 / 19$ (19.3/9.0\%) & $11 / 5(5.2 / 2.4 \%)$ & $4 / 0(1.9 / 0.0 \%)$ & $1 / 0(0.5 / 0.0 \%)$ & $15 / 0(7.1 / 0.0 \%)$ & $140 / 188(66.0 / 88.7 \%)$ \\
\hline Naikhongchhari & 181 & 18/16 (9.9/8.8\%) & 9/4 (5.0/2.2\%) & $1 / 0(0.6 / 0.0 \%)$ & $3 / 0(1.7 / 0.0 \%)$ & $9 / 0(5.0 / 0.0 \%)$ & $141 / 161(77.9 / 89.0 \%)$ \\
\hline Lama & 215 & 21/17 (9.8/7.9\%) & $4 / 3(1.9 / 1.4 \%)$ & $1 / 0(0.5 / 0.0 \%)$ & 0/0 (0.0/0.0\%) & $8 / 0$ (3.7/0.0\%) & $181 / 195(84.2 / 90.7 \%)$ \\
\hline Ali Kadam & 189 & $12 / 10(6.3 / 5.3 \%)$ & 4/2 (1.9/0.9\%) & 0/0 (0.0/0.0\%) & 0/0 (0.0/0.0\%) & $6 / 0$ (2.8/0.0\%) & $167 / 177(88.4 / 93.7 \%)$ \\
\hline
\end{tabular}

'Geometric mean.

${ }^{2} \mathrm{n}=1$.

mixed infections. Plasmodium falciparum gametocytes were detected by microscopy in 11 (2.5\%, 95\% CI: 1.3-4.6) individuals, seven of whom had only gametocytes.

With 188 cases (36.3\%, 95\% CI: 32.2-40.6) the malaria prevalence in individuals under 15 years was significant higher $(\mathrm{p}<0.01)$ compared to older participants $(\mathrm{N}=247$, 27.4\%, 95\% CI: 24.6-30.5). A significantly higher malaria prevalence $(\mathrm{p}=0.015)$ was found in males $(\mathrm{N}=220,34.0 \%$, 95\% CI: 30.4-37.8) as compared to females $(\mathrm{N}=215$, $27.9 \%$, 95\% CI: 24.8-31.2).

The overall geometric mean parasite density determined by microscopy was 707 parasites/ $\mu \mathrm{l}$ (95\% CI: 565-883) for $P$. falciparum and 345 parasites $/ \mu \mathrm{l}$ (95\% CI: 246-484) for P. vivax. Parasite densities in individuals younger than 15 years were significantly higher $(\mathrm{p}<0.01)$.
Out of a total of 435 PCR malaria-positive individuals 335 (77.0\%, 95\% CI: 72.7-80.8) were classified as asymptomatic, $86(19.8 \%, 95 \%$ CI: 16.2-23.9) as oligosymptomatic, and 14 (3.2\%, 95\% CI: 1.8-5.5) symptomatic cases were found. Significantly $(\mathrm{p}<0.01)$ more asymptomatic cases $(\mathrm{N}=208)$ were recorded among participants older than 15 years compared to younger individuals $(\mathrm{n}=127)$. In individuals infected with $P$. falciparum or $P$. vivax no difference $(\mathrm{P}>0.05)$ was found between the proportion of asymptomatic and oligosymptomatic clinical cases (Table 3).

Out of 416 households in 223 (53.6\%, 95\% CI: 48.758.5) at least one member of the household tested positive for malaria, in 64 households $(15.4 \%, 95 \% \mathrm{CI}$ : 12.1-19.3) two people tested positive for malaria and in 56 (13.5\%, 95\% CI: 10.4-17.2) households three or more individuals tested positive by PCR. 
Table 3 Distribution of symptomatic, oligosymptomatic and asymptomatic PCR/microscopy positive malaria cases during monsoon and dry season

\begin{tabular}{llll}
\hline Survey I (monsoon season) & Symptomatic malaria cases & Oligosymtomatic malaria cases & Asymptomatic malaria cases \\
\hline P.f. & $11 / 5(4.3 / 3.1 \%)$ & $52 / 41(20.3 / 25.5 \%)$ & $193 / 115(75.4 / 71.4 \%)$ \\
P. v. & $2 / 1(3.4 / 2.7 \%)$ & $12 / 8(20.3 / 21.6 \%)$ & $45 / 28(76.3 / 75.7 \%)$ \\
P. m. & $0 / 0(0.0 / 0.0 \%)$ & $1 / 0(12.5 / 0.0 \%)$ & $7 / 0(87.5 / 0.0 \%)$ \\
P. o. & $0 / 0(0.0 / 0.0 \%)$ & $2 / 0(33.3 / 0.0 \%)$ & $4 / 0(66.7 / 0.0 \%)$ \\
Mixed infections & $1 / 0(0.0 / 0.9 \%)$ & $19 / 1(17.9 / 25.0 \%)$ & $86 / 3(81.1 / 75.0 \%)$ \\
Total & $14 / 6(3.2 / 3.0 \%)$ & $86 / 50(19.8 / 24.7 \%)$ & $335 / 146(77.0 / 72.3 \%)$ \\
\hline Survey II (dry season) & & & $58 / 23(85.3 / 92.0 \%)$ \\
P.f. & $0 / 0(0.0 / 0.0 \%)$ & $10 / 2(14.7 / 8.0 \%)$ & $22 / 5(88.0 / 71.4 \%)$ \\
P. v. & $0 / 0(0.0 / 0.0 \%)$ & $3 / 2(12.0 / 28.6 \%)$ & $5 / 0(0.0 / 100 \%)$ \\
P. m. & $0 / 0(0.0 / 0.0 \%)$ & $0 / 0(0.0 / 0.0 \%)$ & $1 / 0(0.0 / 100 \%)$ \\
P. . & $0 / 0(0.0 / 0.0 \%)$ & $0 / 0(0.0 / 0.0 \%)$ & $17 / 3(100 / 100 \%)$ \\
Mixed infections & $13 / 4(11.2 / 11.4 \%)$ & $103 / 31(88.8 / 88.6 \%)$ \\
Total & $0 / 0(0.0 / 0.0 \%)$ & & \\
\hline
\end{tabular}

\section{Subdistricts/Upazilas}

Plasmodium falciparum was the predominant species in all subdistricts. The highest malaria prevalence was found in the eastern subdistricts Rowangchari and Thanchi, followed by Bandarban Sadar, Ruma, Naikhongchhari, and Lama. The lowest malaria prevalence was detected in Ali Kadam, which shares only a short stretch of border with Myanmar. Malaria prevalence among the seven subdistricts is shown in detail in Table 2. Significantly higher malaria prevalence $(\mathrm{p}<0.01)$ was seen in the northern and northeastern subdistricts (Bandarban Sadar, Rowangchhari, Ruma, and Thanchi) located in the foothills close to the Indian/Myanmar boarder compared with the western subdistricts (Lama, Ali Kadam and Naikhongchhari) in or closer to the plains (Figure 2). At village level the highest malaria prevalence by PCR with 71.4\% (95\% CI: 53.5-84.8) was found in Bagan village in Ruma subdistrict and the lowest with $1.2 \%$ (95\% CI: 0.06-7.3) in Memberpara village in Lama subdistrict $(\mathrm{p}<0.0001)$.

\section{Spleen rate}

Out of a total of 350 children aged two to nine years, 65 had a palpable spleen (spleen rate: $18.6 \%, 95 \%$ CI: $14.7-$ 23.1); 91 of them $(26.0 \%, 95 \%$ CI: $21.6-31.0)$ were slidepositive for malaria either for $P$. falciparum or $P$. vivax. A total of 121 (34.6\%, 95\% CI: 29.6-39.8) children tested positive by PCR for any of the four malaria species. Thirty-eight (10.9\%, 95\% CI: 7.9-14.7) and 48 (13.7\%, 95\% CI: 10.4-17.9) children were malaria microscopypositive or PCR-positive and had an enlarged spleen at the same time. Sensitivity, specificity, positive (PPV) and negative predictive values (NPV) of spleen enlargement for malaria in this population are shown in Table 4 using microscopy or PCR as reference method. The Venn diagram showing relationship between spleen rate, microscopy and PCR positive children aged two to nine years is shown in Figure 3.

\section{Winter survey II}

From the 436 individuals included in the winter survey (Table 5) only 35 individuals $(8.0 \%, 95 \%$ CI: $5.7-11.1)$ were slide-positive for malaria, however 116 (26.6\%, 95\% CI: 22.6-31.1) tested positive by PCR. Plasmodium falciparum accounted for $58.6 \%$, P. vivax for $21.6 \%$, P. malariae for $4.3 \%$, and P. ovale for $0.9 \%$ of all PCR malaria-positive individuals, the remaining $14.7 \%$ were mixed infections.

Plasmodium falciparum gametocytes were detected by microscopy in four (3.5\%, 95\% CI: 1.1-9.1) individuals of whom only one also had asexual parasites. Malaria prevalence within all participants in the winter survey (dry season) was not significantly $(\mathrm{p}=0.117)$ lower compared to the summer survey.

No patient testing positive for malaria was febrile at the time of the survey, therefore 103 (88.8\%, 95\% CI: 81.3-93.7) were classified as asymptomatic and 13 (11.2\%, 95\% CI: 6.3-18.7) as oligosymptomatic (Table 3).

The geometric mean parasite densities were 487 asexual parasites $/ \mu \mathrm{l}$ (95\% CI: 281-845) for P. falciparum and 751 (95\% CI: 298-1,894) for P. vivax, respectively. No statistically difference $(p>0.05)$ was found between the parasite rate in summer and winter survey.

From a total of 172 households, in 77 (44.8\%, 95\% CI: 37.3-52.5) at least one member tested positive for malaria, in 27 (15.7\%, 95\% CI: 1.4-7.8) households two individuals and in seven (4.1\%, 95\% CI: 1.8-8.5) households three or more people tested positive for malaria. 


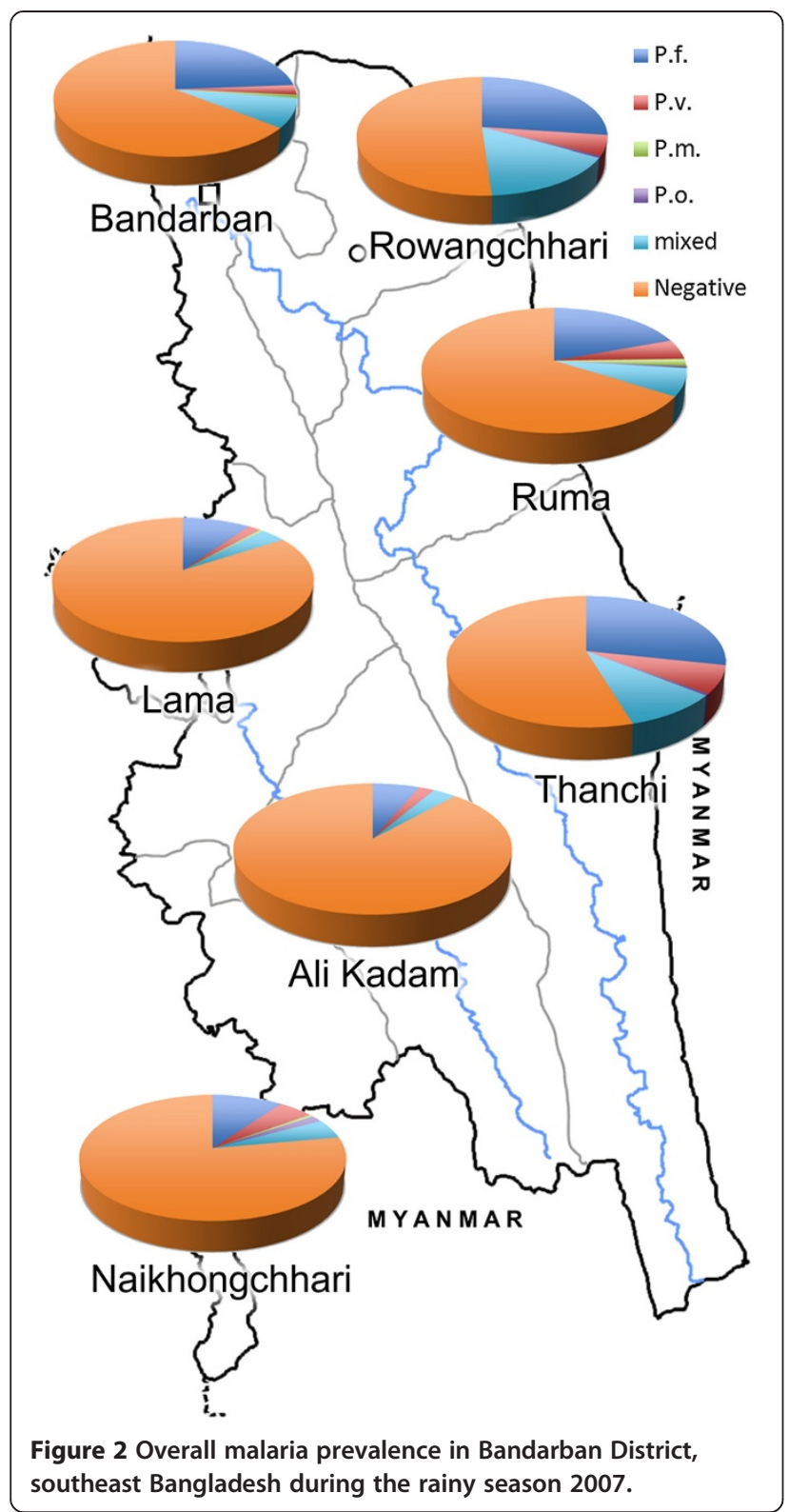

Table 4 Spleen enlargement as predictor for malaria in children two to nine years old

\begin{tabular}{|c|c|c|c|c|c|}
\hline \multicolumn{6}{|c|}{ PCR/microscopy (\%) } \\
\hline & Sensitivity & Specificity & PPV & NPV & $\begin{array}{l}\text { Malaria } \\
\text { prevalence }\end{array}$ \\
\hline $\begin{array}{l}\text { Survey } \\
\text { I }\end{array}$ & $39.7 / 41.8$ & $92.6 / 89.6$ & $\begin{array}{l}73.8 / \\
58.5\end{array}$ & $\begin{array}{l}74.4 / \\
81.4\end{array}$ & $34.6 / 26.0$ \\
\hline $\begin{array}{l}\text { Survey } \\
\text { ॥ }\end{array}$ & $13.3 / 25.0$ & $92.5 / 91.0$ & $\begin{array}{l}44.4 / \\
36.4\end{array}$ & $\begin{array}{l}70.5 / \\
85.5\end{array}$ & $30.9 / 17.0$ \\
\hline
\end{tabular}

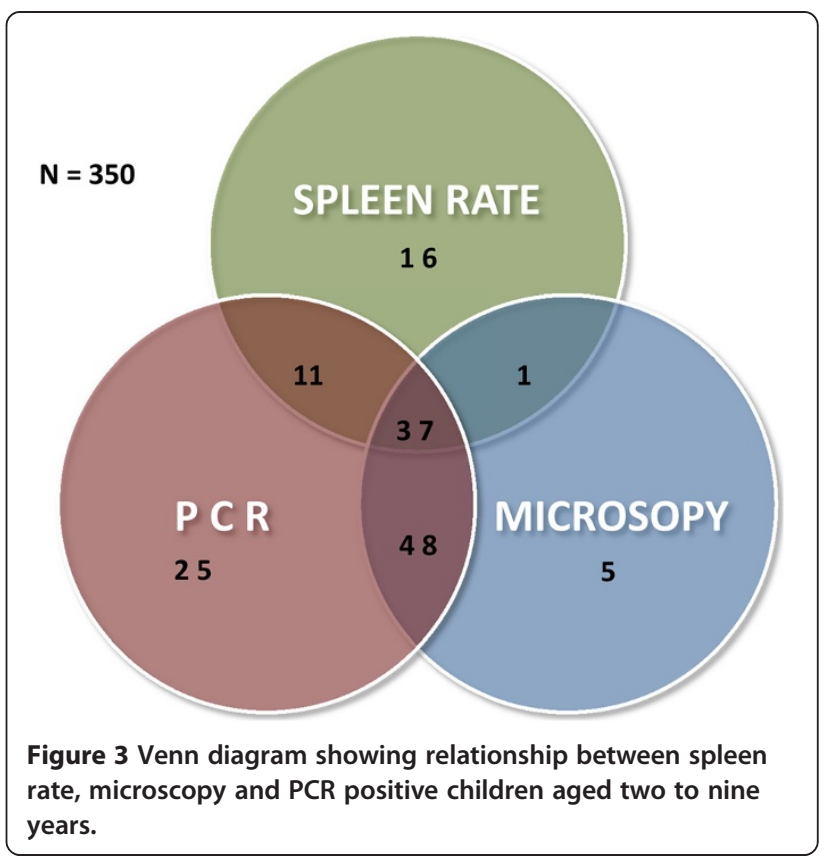

\section{Subdistricts/Upazilas}

In the winter survey the highest malaria prevalence by subdistrict was found in Bandarban Sadar (29.7\%, 95\% CI: $24.4-35.5)$ followed by Rowangchhari $(27.1 \%, 95 \%$ CI: 18.8-37.3), and the lowest malaria prevalence was detected in Ruma (13.4\%, 95\% CI: 6.7-24.5).

\section{Splenomegaly}

Out of 97 children aged two to nine years, nine $(9.3 \%$, 95\% CI: 4.6-17.3) had a palpable spleen and with $30.9 \%$ $(\mathrm{N}=30$; 95\% CI: 22.2-41.2) the parasite prevalence by PCR in survey II was again high but not significantly different from survey I $(p=0.584)$. Malaria-positive PCR and an enlarged spleen at the same time were found in four $(4.1 \%, 95 \%$ CI: $1.3-10.8)$ children two to nine years old. With $9.3 \%$ the spleen rate in winter was also lower than in summer $(18.6 \% ; \mathrm{p}=0.043)$. Sensitivity, specificity, PPV and NPV of spleen enlargement for malaria in the winter survey are shown in Table 4 .

\section{Discussion}

Malaria is a major public health problem in southeastern Bangladesh and remains one of the most common reasons for hospital admissions during the malaria season [15]. Mapping of high-risk areas is essential for planning health interventions [37]. The primary objective of this investigation was to establish detailed baseline data on the prevalence and distribution of malaria in both symptomatic and asymptomatic carriers of Plasmodium parasites in southeastern Bangladesh.

Three major observations can be deducted from these cross-sectional surveys. First, this study demonstrates 
Table 5 Malaria prevalence in three Bandarban subdistricts (Survey II)

\begin{tabular}{|c|c|c|c|c|c|c|c|}
\hline \multirow[t]{2}{*}{ Bandarban district } & \multirow[b]{2}{*}{ No } & \multicolumn{2}{|l|}{ PCR/Microscopy } & \multirow[b]{2}{*}{ P. $m$. } & \multirow[b]{2}{*}{ P. o. } & \multirow[b]{2}{*}{ Mixed } & \multirow[b]{2}{*}{ Negative } \\
\hline & & P.f. & P. v. & & & & \\
\hline \multicolumn{8}{|l|}{ Sex } \\
\hline Male & 178 & 38/17 (21.3/9.6\%) & 9/3 (5.1/1.7\%) & 1/0 (0.6/0.0\%) & $1 / 0(0.6 / 0.0 \%)$ & $8 / 0(4.5 / 0.0 \%)$ & $121 / 158(68.0 / 88.8 \%)$ \\
\hline Female & 258 & 30/8 (11.6/3.1\%) & $16 / 5$ (6.2/1.9\%) & 4/0 (1.6/0.0\%) & 0/0 (0.0/0.0\%) & 9/1 (3.5/0.4\%) & 199/244 (77.1/94.6\%) \\
\hline \multicolumn{8}{|l|}{ Male/Age (years) } \\
\hline $0-7$ & 42 & 9/6 (21.4/14.3\%) & $4 / 2(9.5 / 4.8 \%)$ & 0/0 (0.0/0.0\%) & 0/0 (0.0/0.0\%) & 0/0 (0.0/0.0\%) & 29/34 (69.0/81.0\%) \\
\hline 8-14 & 20 & 4/4 (20.0/20.0\%) & $1 / 0$ (5.0/0.0\%) & 0/0 (0.0/0.0\%) & 0/0 (0.0/0.0\%) & $5 / 0(25 / 0.0 \%)$ & 10/16 (50.0/80.0\%) \\
\hline $15-21$ & 10 & 1/0 (10.0/0.0\%) & $1 / 0(10.0 / 0.0 \%)$ & 0/0 (0.0/0.0\%) & 0/0 (0.0/0.0\%) & 1/0 (10/0.0\%) & 7/10 (70.0/100\%) \\
\hline $22-50$ & 72 & 17/5 (23.6/6.9\%) & 2/1 (2.8/1.4\%) & 1/0 (1.4/0.0\%) & 0/0 (0.0/0.0\%) & 1/0 (1.4/0.0\%) & 51/66 (70.8/91.7\%) \\
\hline$>50$ & 34 & 7/2 (20.6/5.9\%) & $1 / 0(2.9 / 0.0 \%)$ & 0/0 (0.0/0.0\%) & $1 / 0(2.9 / 0.0 \%)$ & $1 / 0(2.9 / 0.0 \%)$ & 24/32 (70.6/94.1\%) \\
\hline \multicolumn{8}{|l|}{ Female/Age (years) } \\
\hline $0-7$ & 45 & 5/1 (11.1/2.2\%) & $1 / 2(2.2 / 4.4 \%)$ & 0/0 (0.0/0.0\%) & 0/0 (0.0/0.0\%) & $3 / 1(6.7 / 2.2 \%)$ & 36/41 (80/91.1\%) \\
\hline 8-14 & 19 & 2/1 (10.5/5.3\%) & $3 / 0(15.8 / 0.0 \%)$ & $1 / 0(5.3 / 0.0 \%)$ & 0/0 (0.0/0.0\%) & $2 / 0(10.5 / 0.0 \%)$ & $11 / 18$ (57.9/94.7\%) \\
\hline $15-21$ & 28 & $3 / 2(10.7 / 7.1 \%)$ & 2/0 (7.1/0.0\%) & 0/0 (0.0/0.0\%) & 0/0 (0.0/0.0\%) & $3 / 0(10.7 / 0.0 \%)$ & 20/26 (71.4/92.9\%) \\
\hline $22-50$ & 127 & 18/4 (14.2/3.1\%) & 9/3 (7.1/2.4\%) & $3 / 0(2.4 / 0.0 \%)$ & 0/0 (0.0/0.0\%) & $1 / 0(0.8 / 0.0 \%)$ & $96 / 120(75.6 / 94.5 \%)$ \\
\hline$>50$ & 39 & 2/0 (5.1/0.0\%) & $1 / 0(2.6 / 0.0 \%)$ & 0/0 (0.0/0.0\%) & 0/0 (0.0/0.0\%) & 0/0 (0.0/0.0\%) & 36/39 (92.3/100\%) \\
\hline \multicolumn{8}{|l|}{ Subdistrict } \\
\hline Bandarban Sadar & 273 & 49/21 (17.9/7.7\%) & 18/7 (6.6/2.6\%) & $4 / 0(1.5 / 0.0 \%)$ & $1 / 0(0.4 / 0.0 \%)$ & 9/0 (3.3/0.0\%) & 192/245 (70.3/89.7\%) \\
\hline Rowangchhari & 96 & 15/4 (15.6/4.2\%) & $4 / 0(4.2 / 0.0 \%)$ & $1 / 0(1.0 / 0.0 \%)$ & 0/0 (0.0/0.0\%) & 6/1 (6.3/1.0\%) & 70/91 (72.9/94.8\%) \\
\hline Ruma & 67 & $4 / 0(6.0 / 0.0 \%)$ & $3 / 1(4.5 / 1.5 \%)$ & 0/0 (0.0/0.0\%) & 0/0 (0.0/0.0\%) & $2 / 0(3.0 / 0.0 \%)$ & $58 / 66$ (86.6/98.5\%) \\
\hline
\end{tabular}

that malaria is meso-endemic in the region and is concentrated in rural communities [38] where the intensity of transmission is largely dependent on environmental variables. Haque et al. have previously reported for this region that environmental factors, such as proximity to forest, household density, and elevation tend to be significantly and positively correlated with malaria risk [39]. The development of immunity is insufficient to prevent the effect of malaria on all age groups [35]. A spleen rate of $18.6 \%$ (proportions of splenomegaly $>10 \%$ are considered to be related to malaria [35]) and malaria prevalence by microscopy of $14.2 \%$ in the rainy and $7.8 \%$ in dry season, show that malaria is meso-endemic throughout the year in this part of Bangladesh. The spleen rate and the higher malaria prevalence in children are further indicators of meso-endemicity and suggest that transmission occurs within the villages $[35,38]$.

Second, malaria prevalence was significantly higher in the northern and eastern subdistricts that are located in the hilly areas bordering Myanmar and Rangamati, another endemic district, whereas endemicity was lower in western and southern subdistricts in or close to the coastal plains, which are more accessible and where access to health care facilities is better. The collected data indicate a level of malaria transmission similar to some African countries, such as Gabon [21], Somalia [40] or Mozambique [41].
Previous studies from India and Indonesia also detected similar parasite prevalence rates $[42,43]$.

Third, a large reservoir of asymptomatic, parasitaemic individuals that are likely to act as a source of infection, was observed in both surveys. The absence of malaria-like symptoms may be an indication of a certain level of immunity in rural communities. Although generally considered to be a typical feature of malaria in highly endemic regions in Africa, a number of studies from Brazil, Peru, Thailand, Cambodia, Myanmar, Vietnam, eastern Indonesia, and Papua New Guinea have reported the existence of asymptomatic malaria infections outside of Africa and in areas with lower endemicity [34,43-49]. This survey indicates a similar proportion of asymptomatic malaria carriers as previously reported from Vietnam [50], Indonesia [43] and Cambodia [45].

Naturally acquired immunity against $P$. falciparum, which is believed to build up with long-term exposure to malaria and presents with lower parasite densities and fewer clinical malaria episodes in older children and adults, has been reported from endemic areas in Myanmar, eastern Indonesia and India [42]. In areas with lower transmission intensity, the age at which clinical immunity develops tends to shift to an older age [42]. Malaria prevalence, parasite density and the number of clinical malaria cases were higher in children under 15 years. 
As previously reported by Alves et al. [46], asymptomatic carriers may act as a reservoir for parasites and are a likely source of infection. However, treatment is typically only provided to symptomatic patients as asymptomatic carriers are rarely seen and/or diagnosed at health care facilities. Particularly in times of malaria elimination, asymptomatic malaria carrier with a low parasitaemia will present new challenges for malaria control in the region where malaria diagnosis is mainly based on microscopy and RDT.

Limitations of this study include all potential shortcomings of a point-prevalence study as well as the potential bias arising from the fact that only one district has been surveyed which may not be representative for all 13 malaria endemic districts in Bangladesh. Secondly, there was some overlap with the previously reported cross-sectional survey based on RDTs [15], which, however, provides far less detailed epidemiological data.

\section{Conclusions}

The surveys showed that there are areas in Bangladesh with prevalence rates comparable to those found in malaria-endemic regions of tropical Africa. This study indicates, in accordance with other studies from Southeast Asia, that there is still a substantial proportion of asymptomatic, parasitaemic individuals in Bangladesh that may act as a silent reservoir for malaria transmission. This has major implications for ongoing malaria control programs in Bangladesh that are based on prevention of infection through bed nets and treatment of symptomatic patients. Particularly considering ongoing elimination efforts these findings highlight the need for new intervention strategies targeting all infections, symptomatic as well as asymptomatic, for reducing potential sources of infection and for interrupting the transmission cycle. Based on this study, it is evident that malaria remains an important public health problem in the southeastern part of Bangladesh. Further research is needed to determine the role of asymptomatic individuals for malaria transmission in the area.

\section{Competing interests}

The authors declare that they have no competing interests.

\footnotetext{
Authors' contributions

HN contributed to all steps from elaboration to the final review (study design, study coordination, overall supervision, data analysis and manuscript review). PS, KT, PSW, BL, MJ supervised and carried out the surveys (three study teams worked simultaneously during the summer survey) and data collection in the field. PS, BL and KT contributed to implementation, to data entry and data analysis. PS wrote the first draft of the manuscript. BL and KT contributed to the writing of the manuscript. $\mathrm{RH}$ helped to design the study protocol, monitored laboratory quality and corrected the manuscript. WAK participated in the coordination of patient samples collection in the field, drafted the manuscript and helped to analyze the data. WG helped to design the study protocol and revised the final manuscript. H-PF and VEH carried out the molecular genetic studies. All authors read, approved and gave their consent to the final manuscript.
}

\section{Acknowledgements}

We wish to thank all the people who participated in these surveys, the Ministry of Health and Family Welfare, the staff of the Sadar Hospital Bandarban and the members of the Civil Surgeon's office Bandarban, Bangladesh for their cooperation and assistance as well as the Bangladesh Army for their assistance in the field.

\section{Author details}

${ }^{1}$ Institute of Specific Prophylaxis and Tropical Medicine, Medical University of Vienna, Kinderspitalgasse 15, Vienna 1090, Austria. ${ }^{2}$ MARIB, Malaria Research Initiative Bandarban, Bandarban, Bangladesh. ${ }^{3}$ Department of Internal Medicine I, Division of Infectious Diseases and Tropical Medicine, Medical University of Vienna, Vienna, Austria. ${ }^{4}$ Department of Pathobiology, Institute of Parasitology, University of Veterinary Medicine Vienna, Vienna, Austria. ${ }^{5}$ International Centre for Diarrhoeal Disease Research Bangladesh, Dhaka, Bangladesh.

Received: 9 October 2013 Accepted: 22 December 2013 Published: 9 January 2014

\section{References}

1. World Health Organization: World Malaria Report 2012. http://www.who.int/ malaria/publications/world_malaria_report_2012/wmr2012_no_profiles.pdf.

2. Cui L, Yan G, Sattabongkot J, Cao Y, Chen B, Chen X, Fan Q, Fang Q, Jongwutiwes S, Parker D, Sirichaisinthop J, Kyaw MP, Su XZ, Yang H, Yang Z, Wang B, Xu J, Zheng B, Zhong D, Zhou G: Malaria in the greater Mekong subregion: heterogeneity and complexity. Acta Trop 2012, 121:227-239.

3. Noedl H, Se Y, Schaecher K, Smith BL, Socheat D, Fukuda MM: Artemisinin resistance in Cambodia 1 (ARC1) study consortium: evidence of artemisinin-resistant malaria in western Cambodia. N Engl J Med 2008, 359:2619-2620.

4. Noedl H, Se Y, Sriwichai S, Schaecher K, Teja-Isavadharm P, Smith B, Rutvisuttinunt W, Bethell D, Surasri S, Fukuda MM, Socheat D, Chan Thap L: Artemisinin resistance in Cambodia: a clinical trial designed to address an emerging problem in Southeast Asia. Clin Infect Dis 2010, 51:e82-e89.

5. Noedl H, Socheat D, Satimai W: Artemisinin-resistant malaria in Asia. N Engl J Med 2009, 361:540-541.

6. Phyo AP, Nkhoma S, Stepniewska K, Ashley EA, Nair S, McGready R, Ler Moo C, Al-Saai S, Dondorp AM, Lwin KM, Singhasivanon P, Day NP, White NJ, Anderson TJ, Nosten F: Emergence of artemisinin-resistant malaria on the Western border of Thailand: a longitudinal study. Lancet 2012, 379:1960-1966.

7. Starzengruber P, Swoboda P, Fuehrer HP, Khan WA, Hofecker V, Siedl A, Fally M, Graf O, Teja-Isavadharm P, Haque R, Ringwald P, Noedl H: Current status of artemisinin-resistant falciparum malaria in South Asia: a randomized controlled artesunate monotherapy trial in Bangladesh. PLoS One 2012, 7:e52236.

8. World Health Organization: World Malaria Report 2011. http://www.who.int/ malaria/world_malaria_report_2011MMR2011_noprofiles_lowres.pdf.

9. Bangali AM, Mahmood MAH, Rahman M: The malaria situation in Bangladesh. Mekong Malaria Forum 2000, 6:20-24.

10. Faiz MA, Yunus EB, Rahman MR, Hossain MA, Pang LW, Rahman ME, Bhuiyan SN: Failure of national guidelines to diagnose uncomplicated malaria in Bangladesh. Am J Trop Med Hyg 2002, 67:396-399.

11. Thriemer K, Haque R, Wagatsuma Y, Salam MA, Akther S, Attlmayr B, Fukuda M, Schaecher K, Miller RS, Noedl H: Therapeutic efficacy of quinine plus sulfadoxine-pyrimethamine for the treatment of uncomplicated falciparum malaria in Bangladesh. Am J Trop Med Hyg 2006, 75:645-649.

12. Haque R, Thriemer K, Wang Z, Sato K, Wagatsuma Y, Salam MA, Akther S, Akter J, Fukuda M, Miller RS, Noedl H: Therapeutic efficacy of artemetherlumefantrine for the treatment of uncomplicated Plasmodium falciparum malaria in Bangladesh. Am J Trop Med Hyg 2007, 76:39-41.

13. Attlmayr B, Thriemer $K$, Haque R, Wagatsuma Y, Abdus Salam M, Akhter S, Fukuda M, Schaecher K, Miller RS, Noedl H: In vitro antimalarial drug resistance in Southeastern Bangladesh. Wien Klin Wochenschr 2006, 118:58-61.

14. Noedl H, Faiz MA, Yunus EB, Rahman MR, Hossain MA, Samad R, Miller RS, Pang LW, Wongsrichanalai C: Drug-resistant malaria in Bangladesh: an in vitro assessment. Am J Trop Med Hyg 2003, 68:140-142.

15. Haque U, Ahmed SM, Hossain S, Huda M, Hossain A, Alam MS, Mondal D, Khan WA, Khalequzzaman M, Haque R: Malaria prevalence in endemic districts of Bangladesh. PLoS One 2009, 4:e6737. 
16. Fuehrer HP, Starzengruber P, Swoboda P, Khan WA, Matt J, Ley B, Thriemer K, Haque R, Yunus EB, Hossain SM, Walochnik J, Noedl H: Indigenous Plasmodium ovale malaria in Bangladesh. Am J Trop Med Hyg 2010, 83:75-78.

17. Ouédraogo AL, Bousema T, Schneider P, De Vlas SJ, Ilboudo-Sanogo E, Cuzin-Ouattara N, Nébié I, Roeffen W, Verhave JP, Luty AJ, Sauerwein R: Substantial contribution of submicroscopical Plasmodium falciparum gametocyte carriage to the infectious reservoir in an area of seasonal transmission. PloS One 2009, 4:e8410.

18. Sharp BL, Kleinschmidt I, Streat E, Maharaj R, Barnes KI, Durrheim DN, Ridl FC, Morris N, Seocharan I, Kunene S, LA Grange JJ, Mthembu JD, Maartens F, Martin CL, Barreto A: Seven years of regional malaria control collaboration-Mozambique, South Africa, and Swaziland. Am J Trop Med Hyg 2007, 76:42-47.

19. Mabunda S, Aponte JJ, Tiago A, Alonso P: A country-wide malaria survey in Mozambique. II. Malaria attributable proportion of fever and establishment of malaria case definition in children across different epidemiological settings. Malar J 2009, 8:74

20. Vafa M, Troye-Blomberg M, Anchang J, Garcia A, Migot-Nabias F: Multiplicity of Plasmodium falciparum infection in asymptomatic children in Senegal: relation to transmission, age and erythrocyte variants. Malar J 2008, 7:17.

21. Dal-Bianco MP, Köster KB, Kombila UD, Kun JF, Grobusch MP, Ngoma GM, Matsiegui PB, Supan C, Salazar CL, Missinou MA, Issifou S, Lell B, Kremsner P: High prevalence of asymptomatic Plasmodium falciparum infection in Gabonese adults. Am J Trop Med Hyg 2007, 7:939-942.

22. United Nations: Designing Household Survey Samples: Practical Guidelines. Studies in Methods, Series F No.98. New York; 2008.

23. Moody A: Rapid diagnostic tests for malaria parasites. Clin Microbiol Rev 2002, 15:66-78.

24. Meena M, Joshi D, Joshi R, Sridhar S, Waghdhare S, Gangane N, Kalantri SP: Accuracy of a multispecies rapid diagnostic test kit for detection of malarial parasite at the point of care in a low endemicity region. Trans R Soc Trop Med Hyg 2009, 103:1237-1244.

25. World Health Organization: Basic malaria microscopy. Geneva: WHO; 1991. Reprint 1995).

26. Chaorattanakawee S, Natalang O, Hananantachai H, Nacher M, Brockman A, Krudsood S, Looareesuwan S, Patarapotikul J: Storage duration and polymerase chain reaction detection of Plasmodium falciparum from blood spots on filter paper. Am J Trop Med Hyg 2003, 69:42-44.

27. Bereczky S, Mårtensson A, Gil JP, Färnert A: Rapid DNAextraction from archive blood spots on filter paper for genotyping of Plasmodium falciparum. Am J Trop Med Hyg 2005, 72:249-251.

28. Snounou G, Viriyakosol S, Zhu XP, Jarra W, Pinheiro L, Do Rosario VE, Thaithong S, Brown KN: High sensitivity of detection of human malaria parasites by the use of nested polymerase chain reaction. Mol Biochem Parasitol 1993, 61:315-320.

29. Snounou G, Singh B: Nested PCR analysis of Plasmodium parasites. Methods Mol Med 2002, 72:189-203.

30. Singh B, Bobogare A, Cox-Singh J, Snounou G, Abdullah MS, Rahman HA: A genus- and species-specific nested polymerase chain reaction malaria detection assay for epidemiologic studies. Am J Trop Med Hyg 1999, 60:687-692.

31. Fuehrer HP, Fally MA, Habler VE, Starzengruber P, Swoboda P, Noedl H: Novel nested direct PCR technique for malaria diagnosis using filter paper samples. J Clin Microbiol 2011, 49:1628-1630.

32. Calderaro A, Piccolo G, Perandin F, Gorrini C, Peruzzi S, Zuelli C, Ricci L, Manca N, Dettori G, Chezzi C, Snounou G: Genetic polymorphisms influence Plasmodium ovale PCR detection accuracy. J Clin Microbiol 2007, 45:1624-1627

33. Fuehrer HP, Stadler MT, Buczolich K, Bloeschl I, Noedl H: Two techniques for simultaneous identification of Plasmodium ovale curtisi and Plasmodium ovale wallikeri by use of the small-subunit rRNA gene. J Clin Microbiol 2012, 50:4100-4102.

34. Laishram DD, Sutton PL, Nanda N, Sharma VL, Sobti RC, Carlton JM, Joshi H: The complexities of malaria disease manifestations with a focus on asymptomatic malaria. Malar J 2012, 11:29.

35. Gilles HM, Warrell DA: Bruce-Chwatt's Essential Malariology. 3rd edition. Oxford: Oxford University Press; 1999:368pp.

36. VassarStats: Website for Statistical Computation. http://vassarstats.net.

37. Dev V, Phookan S, Sharma VP, Anand SP: Physiographic and entomologic risk factors of malaria in Assam, India. Am J Trop Med Hyg 2004, 71:451-456.
38. World Health Organization: Global malaria control and elimination: a report of technical review. Geneve, Switzerland; 2008.

39. Haque U, Soares Magalhães RJ, Mitra D, Kolivras KN, Schmidt WP, Haque R, Glass GE: The role of age, ethnicity and environmental factors in modulating malaria risk in Rajasthali, Bangladesh. Malar J 2011, 10:367.

40. Noor AM, Moloney G, Borle M, Fegan GW, Shewchuk T, Snow RW: The use of mosquito nets and the prevalence of Plasmodium falciparum infection in rural South Central Somalia. PLoS One 2008, 3:e2081.

41. Mayor A, Aponte JJ, Fogg C, Saúte F, Greenwood B, Dgedge M, Menendez C, Alonso PL: The epidemiology of malaria in adults in a rural area of southern Mozambique. Malar J 2007, 6:3.

42. Sharma SK, Tyagi PK, Padhan K, Upadhyay AK, Haque MA, Nanda N, Joshi H, Biswas S, Adak T, Das BS, Chauhan VS, Chitnis CE, Subbarao SK: Epidemiology of malaria transmission in forest and plain ecotype villages in Sundargarh District, Orissa, India. Trans R Soc Trop Med Hyg 2006, 100:917-925

43. Karyana M, Burdarm L, Yeung S, Kenangalem E, Wariker N, Maristela $R$, Umana KG, Vemuri R, Okoseray MJ, Penttinen PM, Ebsworth P, Sugiarto P Anstey NM, Tjitra E, Price RN: Malaria morbidity in Papua Indonesia, an area with multidrug resistant Plasmodium vivax and Plasmodium falciparum. Malar J 2008, 7:148.

44. Erhart A, Ngo DT, Phan VK, Ta TT, Van Overmeir C, Speybroeck N, Obsomer $\mathrm{V}$, Le XH, Le KT, Coosemans M, D'alessandro U: Epidemiology of forest malaria in central Vietnam: a large scale cross-sectional survey. Malar J 2005, 4:58

45. Incardona S, Vong S, Chiv L, Lim P, Nhem S, Sem R, Khim N, Doung S, Mercereau-Puijalon O, Fandeur T: Large-scale malaria survey in Cambodia: novel insights on species distribution and risk factors. Malar J 2007, 6:37.

46. Alves FP, Durlacher RR, Menezes MJ, Krieger H, Silva LH, Camargo EP: High prevalence of asymptomatic Plasmodium vivax and Plasmodium falciparum infections in native Amazonian populations. Am J Trop Med Hyg 2002, 66:641-648.

47. Roshanravan B, Kari E, Gilman RH, Cabrera L, Lee E, Metcalfe J, Calderon M, Lescano AG, Montenegro SH, Calampa C, Vinetz JM: Endemic malaria in the Peruvian Amazon region of lquitos. Am J Trop Med Hyg 2003, 69:45-52.

48. Thang ND, Erhart A, Speybroeck N, Hung Le X, Thuan Le K, Hung CT, Ky PV, Coosemans M, D'Alessandro U: Malaria in central Vietnam: analysis of risk factors by multivariate analysis and classification tree models. Malar J 2008, 7:28.

49. Brown T, Smith LS, Oo EK, Shawng K, Lee TJ, Sullivan D, Beyrer C, Richards AK: Molecular surveillance for drug-resistant Plasmodium falciparum in clinical and subclinical populations from three border regions of Burma/ Myanmar: cross-sectional data and a systematic review of resistance studies. Malar J 2012, 11:333.

50. Thang ND, Erhart A, Hung Le X, Thuan Le K, Xa NX, Thanh NN, Ky PV, Coosemans M, Speybroeck N, D'Alessandro U: Rapid decrease of malaria morbidity following the introduction of community-based monitoring in a rural area of central Vietnam. Malar J 2009, 8:3.

\section{doi:10.1186/1475-2875-13-16}

Cite this article as: Starzengruber et al:: High prevalence of asymptomatic malaria in south-eastern Bangladesh. Malaria Journal 2014 13:16.

\section{Submit your next manuscript to BioMed Central and take full advantage of:}

- Convenient online submission

- Thorough peer review

- No space constraints or color figure charges

- Immediate publication on acceptance

- Inclusion in PubMed, CAS, Scopus and Google Scholar

- Research which is freely available for redistribution 